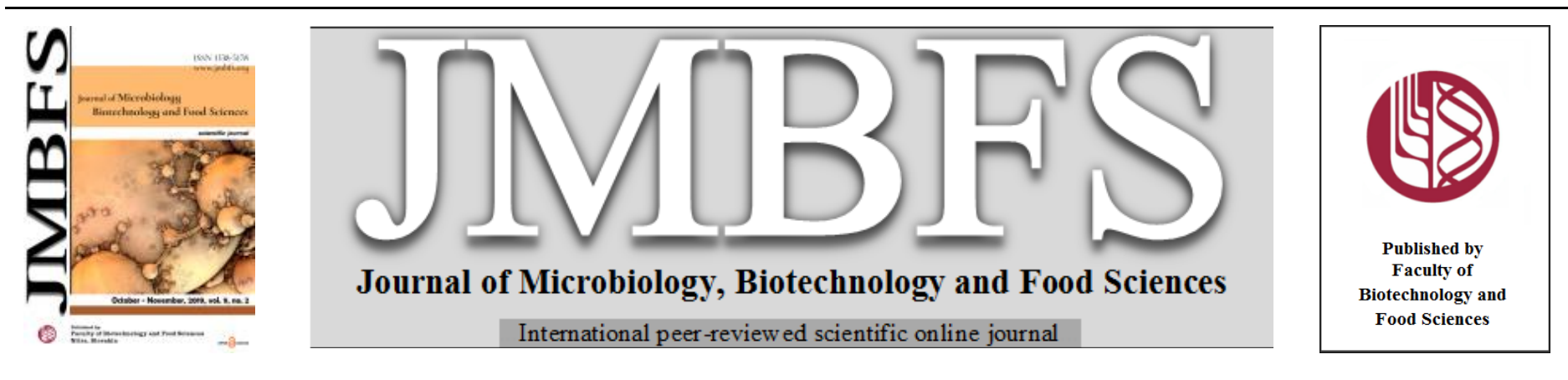

\title{
DEVELOPMENT AND COMPARATIVE EVALUATION OF STORAGE CHANGES IN PROBIOTIC SOY-YOGHURT
}

\author{
Ndife Joel ${ }^{* 1}$, Samaila James ${ }^{2}$, Offia-Olua Blessing ${ }^{1}$ \\ Address(es): \\ ${ }^{1}$ Department of Food Science and Technology, Michael Okpara University of Agriculture, Umudike, Nigeria. \\ ${ }^{2}$ Deptartment of Food Science and Technology, Federal University of Technology, Minna, Nigeria.
}

*Corresponding author: jothel2000@gmail.com

doi: 10.15414/jmbfs.2019.9.2.298-301

ARTICLE INFO

Received 28.1.2019

Revised 30. 4. 2019

Accepted 3. 5. 2019

Published 1. 10. 2019

Regular article

OPEN OACCESS

\begin{abstract}
The addition of probiotics in the fermentation of soy milk products will enhance the health and commercial values of soy milk and create more alternative soy products to the delight of consumers. The survival of Lactobacillus acidophilus and Bifidobacterium lactis probiotics, inoculated into cow milk (PCMY) and soymilk (PSMY) to produce yoghurts and stored for 30 days at $10{ }^{\circ} \mathrm{C}$ were evaluated. The physico-chemical characteristics, probiotic viability and sensory qualities of the yoghurts were assessed. The results of the proximate composition showed that PCMY had higher moisture (30.49\%), protein $(3.49 \%)$ and carbohydrate $(62.31 \%)$ contents than PSMY. At the end of storage, PCMY had higher lactic acid content (1.35\%) than PSMY (1.32 \%). The sugar content of the yoghurts also decreased with storage ( 3 to 4 weeks). There was rapid increase in specific gravity of both PCMY (1.00 to 1.20) and PSMY (1.25 to 1.90). The viscosity of the yoghurts ranged from 1433 to $1673 \mathrm{cP}$ for PCMY and 1467 to $1640 \mathrm{cP}$ for PSMY. The increase in total microbial load was more pronounced in PSMY (2.0 to $4.4 \mathrm{log} \mathrm{cfu} / \mathrm{ml}$ ) than PCMY 1.1 to $3.1 \mathrm{log} \mathrm{cfu} / \mathrm{ml}$ ). The growth of Lactobacillus in PCMY (9.1 log cfu/ml) and PSMY (5.4 log cfu/ml) was higher than that of Bifidobacteria (6.3 and $5.1 \mathrm{log} \mathrm{cfu} / \mathrm{ml}$ ) during storage. PSMY was less preferred to PCMY in terms of taste, texture and overall acceptability because of the beany flavour and low viscosity. The probiotic yoghurt from soymilk was comparable to standard yoghurt with little difference. PSMY will serve favourably as functional milk product with little modification.
\end{abstract}

Keywords: Soy beans, milk, yoghurt, proximate, probiotics, sensory

\section{INTRODUCTION}

Milk and milk products are one of the most consumed foods because of the nutrient composition. However, the high fat content, high cost of milk and the lactose intolerance by some people make the consumption of cow milk and the products less attractive. Probiotic dairy functional foods have become viable innovation in overcoming these challenges (Tamine, 1997; Evangelista et al., 2012; Ndife, 2016).

Probiotics are microorganisms that are believed to provide health benefits when consumed (Granato et al., 2010; Ndife 2016). The World Health Organization's also defined probiotics as live micro-organisms which, when administered in adequate amounts, confer a health benefit on the host (Granato et al., 2010) Most of the probiotic species belong to the genera Lactobacillus and Bifidobacterium (Granato et al., 2010; Ndife, 2016)

Soy milk, due to its high protein and phytochemical content is fast becoming a promising dairy milk substitute to health conscious consumers (Olaoye, 2015; Ndife, 2016). More so, in the last decade, the beneficial effects of soy-based products in the prevention and treatment of chronic diseases have been recognized (Oduro-Obeng and Plahar, 2017). Worldwide, yoghurt, a fermented dairy product has become a suitable alternative by lactose intolerant persons. The trend is to produce yoghurt from plant sources like soya beans. However, the range of soy-based products is still very limited, mostly because of the objectionable characteristic "beany" flavor (Palacios et al., 2009). Nevertheless their biochemical and nutrient components make them attractive imitation milks Hence novel soy-containing foods are becoming more trendy and high in demand (Oduro-Obeng and Plahar, 2017).

Functional foods are limited in the market despite the availability of functional ingredients. The addition of probiotics in the fermentation of soy milk products will enhance the health and commercial values of soy milk and create more alternative soy products to the delight of consumers (Granato et al., 2010; Ndife 2016; Olaoye et al., 2017). This research work is therefore aimed at producing a probiotic soy milk product. The result of this study will inform the dairy industries about the suitability of soy milk and probiotic organisms in adding value to dairy products as functional foods.

\section{MATERIALS AND METHODS}

\section{Raw materials sourcing}

The raw materials; soybean kernel, powdered milk (Dano) used for yoghurt production were purchased at Kaduna main market, Kaduna Nigeria. The commercial probiotic starter culture mini-sachets were purchased from franchise store in Kaduna. The equipments and reagents used were of standard specifications.

Table 1 Product Formulation

\begin{tabular}{lcc}
\hline \multicolumn{1}{c}{ Ingredient } & PCMY & PSMY \\
\hline Cow milk (powdered) & $400 \mathrm{~g}$ & Nil \\
Soy bean kernel (milled) & Nil & 400 \\
Distilled water & $2000 \mathrm{ml}$ & $2000 \mathrm{ml}$ \\
Starter culture & $2.0 \mathrm{~g}$ & $2.0 \mathrm{~g}$ \\
\hline
\end{tabular}

\section{Production of soy yoghurt}

Dry soybean kernels (600 g) were sorted and soaked in warm water for 3 hours The rehydrated beans were dehulled $(400 \mathrm{~g})$, wet milled and boiled for $1 \mathrm{hr}$. The resulting slurry was filtered with a muslin cloth. The filtrate (soy milk), was pasteurized at $65^{\circ} \mathrm{C}$ for 5 minutes; cooled to $42{ }^{\circ} \mathrm{C}$. At this temperature, $2.0 \mathrm{~g}$ of starter culture containing Lactobacillus acidophilus and Bifidobacterium lactis (1 $\mathrm{g}$ each) was added (inoculated) and mixed thoroughly. The inoculated soy milk was incubated for $12 \mathrm{hr}$, after which the fermented product was packaged and stored in the refrigerator at $10{ }^{\circ} \mathrm{C}$. The same procedure was adopted for the production of cow milk yoghurt after reconstitution of the powdered milk. The samples were labelled PCMY and PSMY for the fermented cow milk and soy milk respectively. 


\section{ANALYTICAL METHODS}

\section{Physical properties}

The physical properties: specific gravity, $\mathrm{pH}$, and titratable acidity (TTA), \% brix and viscosity of the samples were determined by standard methods (AOAC, 2005).

\section{Chemical composition}

The proximate composition of the samples, which included: moisture, ash, fat and protein contents were analyzed, using Onwuka (2018) methods. Carbohydrate was determined by difference.

\section{Microbiological assay}

The determination of total microbial count of the milk samples was performed by the method outlined in compendium of methods for the microbiological examination of foods (APHA, 1992) with some modifications.

\section{Enumeration of probiotic microorganisms}

The viability of the probiotics was measured (Vijayalakshmi et al., 2014) immediately after inoculating the probiotic cultures and at 2 weeks intervals during storage. The samples $(10 \mathrm{~g})$ were decimally diluted with sterile peptone water. One $\mathrm{ml}$ of the aliquot dilutions was pour plated in triplicate on MRS agar for Lactobacillus counts. Bifidobacterium sp. was cultured with MRS agar into which was added $0.5 \%$ of dicloxacillin, $1 \%$ of Lithium chloride ( $\mathrm{LiCl}$ ) and $0.5 \%$ of cysteine hydrochloride $(\mathrm{CyHCl})$ was added to inhibit other microbes. The plates were incubated at $38 \pm 1{ }^{\circ} \mathrm{C}$ for $72 \mathrm{hr}$ under aerobic condition for the Lactobacillus sp. and anaerobic condition for the Bifidobacterium sp. The bacterial viability was represented as survival rate. The number of colonies appearing in the incubated plates from respective dilutions were counted, averaged and expressed in logarithmic of colony forming unit per ml of sample $(\log \mathrm{cfu} / \mathrm{ml})$.

\section{SENSORY PROPERTIES EVALUATION}

The sensory attributes of the yoghurt samples were evaluated organoleptically (Iwe, 2010) for appearance, aroma, taste, mouth feel and general acceptability. The test was conducted by a 20 member semi-trained panelist. The panelists were asked to score each attribute based on a 9-point hedonic scale ranging from 1 (dislike extremely) to 9 (like extremely).

\section{STATISTICAL ANALYSIS}

The experiment was of a completely randomized design. The data obtained were in triplicates and expressed as mean with standard error. The results were subjected to variance analyses and differences between means were separated by Duncan's multiple range test using SPSS statistics programme, version 11.0 (Illinois, USA). Significant differences were expressed at $p<0.05$.

\section{RESULTS AND DISCUSSION}

\section{Proximate composition}

The results of the proximate composition of PCMY (cow milk) and PSMY (soymilk) yoghurts after production and before storage are presented in Table 2 The samples have high moisture content above $90.0 \%$ though they were not significantly different at $\mathrm{p}<0.05$. Soymilk was reported to have higher moisture content compared to cow milk (Sampson et al, 2017). This might be because the milk powder was reconstituted with less water. The moisture content of any food is an index of its water activity (Onwuka, 2014). The results also show that the protein and fat contents of the yoghurts were significantly different $(\mathrm{p}<0.05)$ PCMY had higher protein $(3.49 \%)$ than PSMY $(2.02 \%)$. The high protein content in the samples implies that the yoghurt samples could be used to enhance the protein intake of diets (Wang et al., 2015). The ash content of PSMY (1.51 $\%)$ was higher than PCMY $(1.15 \%)$ but with no significant difference $(\mathrm{P}<0.05)$ The results agree with Sampson $\boldsymbol{e t}$ al. (2017) who reported that the ash content of cow milk yoghurt is higher than soy milk yoghurt. Ash content is an index of inorganic mineral elements in the food (Ndife et al., 2011). The fat content of the yoghurt samples ranged from 2.31 to $3.30 \%$ with PSMY having a higher value $(3.30 \%)$ than PCMY $(2.31 \%)$. The soy milk must have derived the higher fat content from soya beans, which are regarded as oil seeds. Hence the reason for the higher oil content than cow milk (Olaoye, 2015; Wang et al., 2015).

The fibre content of PSMY $(0.85 \%)$ was also higher than in PCMY $(0.25 \%)$ According to literature, food with high crude fibre content helps to reduce blood cholesterol levels, accelerate the transit of chyme in the gut as well as increase faecal disposal which is very helpful in weight management (Ndife et al., 2016; Sampson et al., 2017). There was significant difference $(\mathrm{p}<0.05)$ in the carbohydrate contents of PCMY (62.31\%) and PSMY (56.69 \%). Similar trend was reported by Sampson et al. (2017). The high carbohydrate value could be due to the higher total solids of PCMY (Osundahunsi et al., 2007). The samples would contribute considerable nutritive value to spectrum of diets.

Table 2 The Proximate composition of yoghurt samples (\%)

\begin{tabular}{lcc} 
Parameters & PCMY & PSMY \\
\hline Moisture & $30.49^{\mathrm{a}} \pm 0.21$ & $35.63^{\mathrm{b}} \pm 0.64$ \\
Crude protein & $3.49^{\mathrm{a}} \pm 0.11$ & $2.02^{\mathrm{b}} \pm 0.14$ \\
Fat & $2.31^{\mathrm{a}} \pm 0.10$ & $3.30^{\mathrm{b}} \pm 0.08$ \\
Crude fibre & $0.25^{\mathrm{a}} \pm 0.02$ & $0.85^{\mathrm{a}} \pm 0.01$ \\
Ash & $1.15^{\mathrm{a}} \pm 0.20$ & $1.51^{\mathrm{a}} \pm 0.23$ \\
Carbohydrate & $62.31^{\mathrm{a}} \pm 0.46$ & $56.69^{\mathrm{b}} \pm 0.32$ \\
\hline
\end{tabular}

Values are means \pm standard deviation; Rows with different superscript are significantly different $(\mathrm{p}<0.05)$.

\section{Physical properties analysis}

Figure 2 shows the total titratable acidity (TTA) of the yoghurt samples analyzed. It showed an increase in acidity in both samples during the 4 weeks storage period, with an initial leap during the first week of storage. Similar trend was reported by Brandao et al. (2013) for stored yoghurt samples. The increase in lactic acid content ranged from 1.31 to $1.35 \%$ in the yoghurt samples during the 4 weeks storage period. Sample PCMY had higher lactic acid content $(1.35 \%)$ than PSMY $(1.32 \%)$ at the end of storage. The overall changes of the TTA in the study may be suggesting that the fermentative activities of the yoghurt starters still continued in storage (Ndife, 2016). Several authors have also reported the ability of the lactic acid bacteria (LAB) strain to produce considerate quantities of lactic and acetic acids (Brandao et al., 2013; Olaoye et al., 2017; Ndife, 2016) Acid production is desirous in functional probiotic foods. It is also advantageous in food preservation as it prevent the growth of other microbes, especially the pathogenic ones (Evangelista et al., 2012

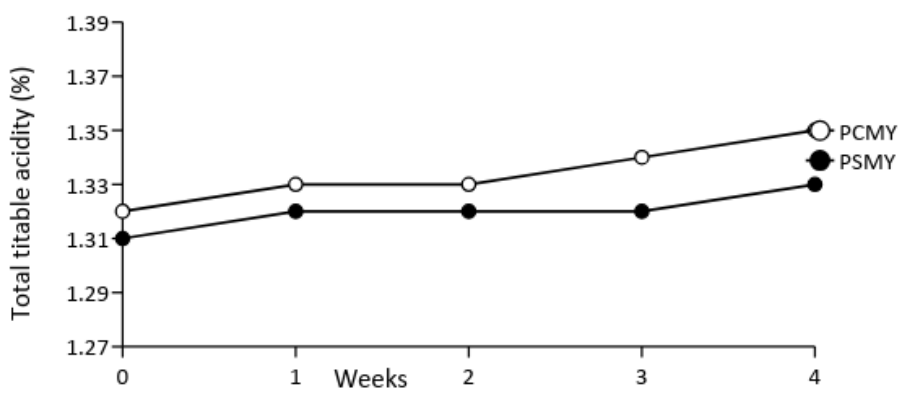

Figure 2 Total titrable acidity of yoghurt samples during storage

The results of the total soluble sugar content (\% Brix) of the yoghurt samples are shown in Figure 3. The sugar content was higher in PCMY (3.00 to $4.50 \%$ ) than in sample PSMY (1.10 to $2.12 \%)$ during storage. There were decreases in the sugar content of the yoghurt samples towards the end of storage (3 to 4 weeks). The sugar contents of PCMY and PSMY were significantly different $(\mathrm{P}<0.05)$ during the storage. The sugar content will surely affect the fermentation $\mathrm{pr}^{\mathrm{oc}} \mathrm{ess}$ (Onwuka, 2014). Brandao et al. (2013) reported that added sugar aided the production of lactic acid during the production of symbiotic soy beverage.

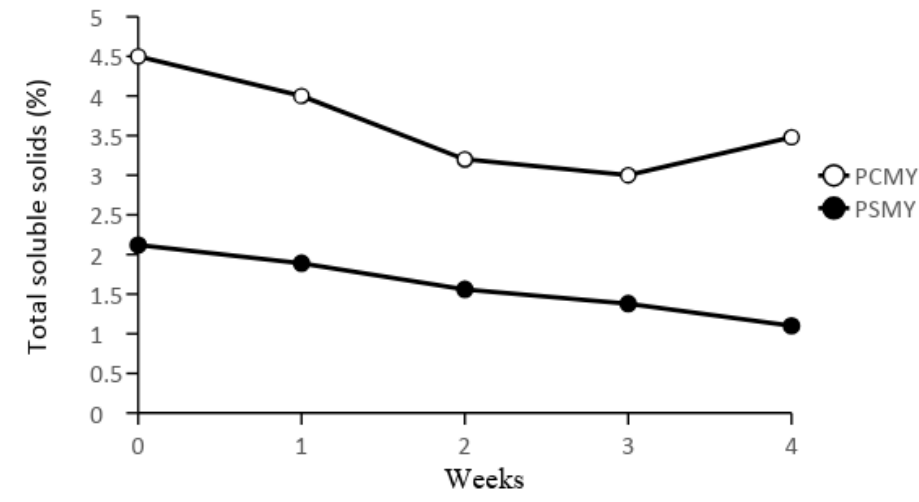

Figure 3 Total soluble sugar of yoghurt samples during storage 
The specific gravity of PCMY and PSMY is shown in Figure 4. PCMY had lower specific gravity (1.00) than PSMY (1.25) after production. There was rapid increase in specific gravity of both PCMY (1.00 to 1.20) and PSMY (1.25 to 1.90) during week one of storage. However the specific gravity of PSMY (0.98) decreased below PCMY (1.18) sample after 2 weeks of storage. PCMY sample maintained an increase, though gradual, during the storage tenure.

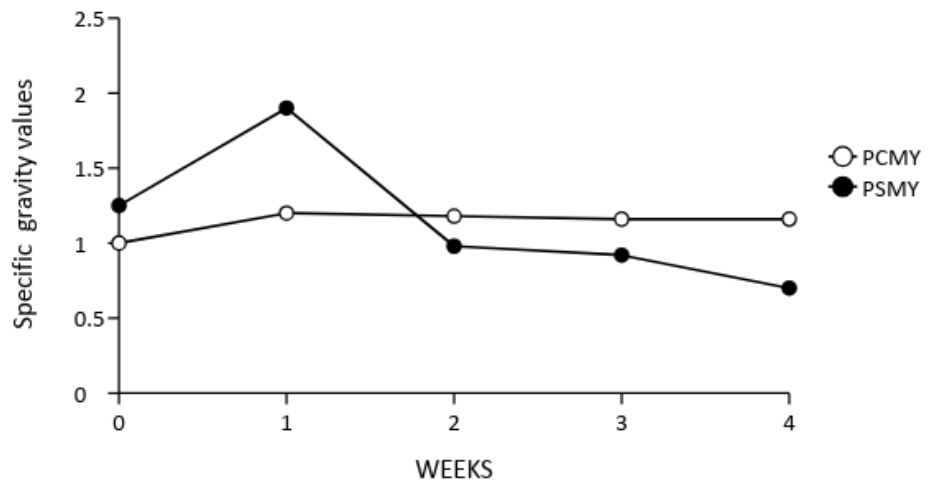

Figure 4 Specific gravity of yoghurt samples during storage

The chemical content of foods influences their viscosity. The viscosity of yoghurt samples increased continually during the storage time (Fig. 5). The viscosity of the yoghurts varied within the range of 1433 to $1673 \mathrm{cP}$ for PCMY and 1467 to $1640 \mathrm{cP}$ for PSMY sample. The viscosity of PCMY $(1433 \mathrm{cP})$, though initially lower than PSMY $(1467 \mathrm{cP})$ at 2 weeks of storage, became more viscous after 4 weeks of storage $(1673 \mathrm{cP})$. The increase in viscosity was due to increase in the total solids content of the samples. Xiaohong $\boldsymbol{e t}$ al. (2017) reported similar trend for fermented soya milk samples while Kaushik and Arora (2017) reported an increase in viscosity for calcium fortified milks. Fermentation reactions proceeded better in PCMY than PSMY. Lactose sugar in cow milk has been reported to be a good substrate for probiotic organisms (Olaoye et al., 2017; Ndife, 2016). Viscosity of food system is usually affected by sugar and other macromolecules through their interaction with the solution or solvent (Trisnawati et al., 2013; Onwuka, 2014).

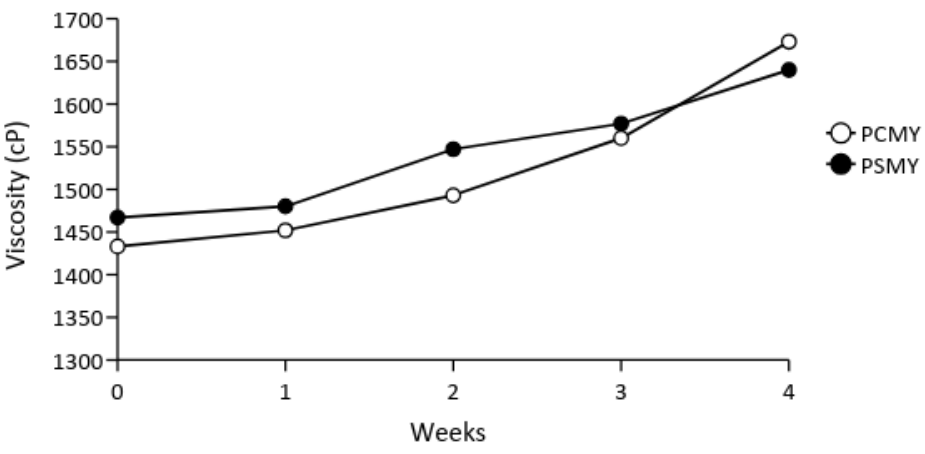

Figure 5 Viscosity of yoghurt samples during Storage

\section{Microbial analysis}

The result of microbiological analysis of the yogurt samples during storage is shown in Figure 6. The total microbial load was more in PSMY (2.2 log cfu/ml) than PCMY (1.1 log cfu/ml) after production. This could be due to contamination during the processing of the soybeans into soy-milk. There was an increase in the total microbial counts in both PCMY and PSMY during the storage period. The increase was more pronounced in PSMY (2.0 to $4.4 \mathrm{log} \mathrm{cfu} / \mathrm{ml}$ ) than PCMY 1.1 to $3.1 \mathrm{log} \mathrm{cfu} / \mathrm{ml}$ ). This was contrary to the report by Jimoh and Kolapo (2013) on the reduction in microbial count when stabilizers where incorporated into yoghurts. The general low microbial counts could be an indication of good manufacturing practice and personal hygiene that was observed during production (Evangelista et al., 2012).

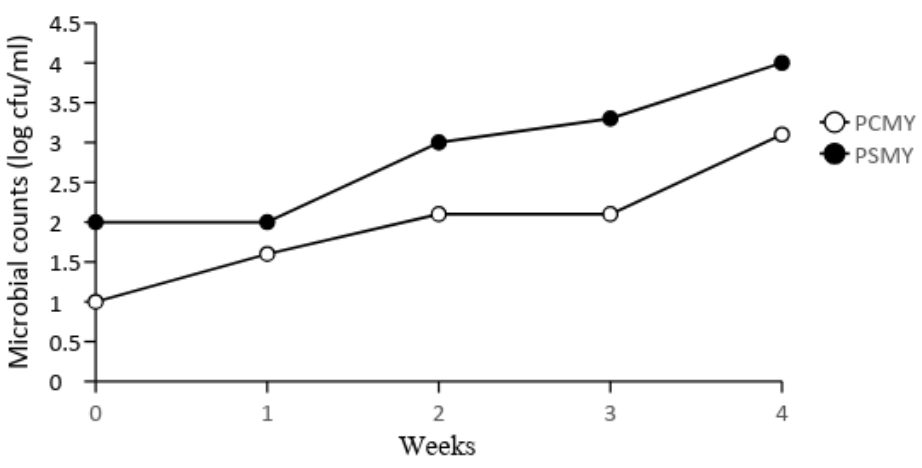

Figure 6 Total microbial counts of yoghurt samples during storage

\section{Probiotic viability}

The viabilities of the both Lactobacillus acidophilus and Bifidobacterium lactis represented by their survival in the yoghurts during storage are shown in Figures 7 and 8 . The probiotic organisms proliferated rapidly in the yoghurt samples during the initial period (1 week) of storage. The growth of Lactobacillus acidophilus in PCMY (9.1 log cfu/ml) and PSMY (5.4 log cfu/ml) was higher than that of Bifidobacterium lactis (6.3 and $5.1 \mathrm{log} \mathrm{cfu} / \mathrm{ml})$ during storage. By week 3 both organism started to decrease in growth. The probiotic viable cell count in PCMY within 3 weeks of storage was within the recommended limits of $7 \log \mathrm{cfu} / \mathrm{ml}$ of viable probiotic cells (Evangelista et al., 2012; Brandao et al., 2013). The survival of Bifidobacteria sp. in PCMY and PSMY was lower than Lactobacillus at refrigerated storage. More so, PCMY supported the growth of the probiotics better than PSMY during the 4 week storage period. The tolerance of the microbial strains to the acidic environment and available substrate represent an important parameter for the survival of probiotic microorganisms in dairy products. Bevilacqua et al. (2012) reported Bifidum sp. to be more acid tolerant $(\mathrm{pH} 2-5)$ and do better at higher temperature of 25 to $30^{\circ} \mathrm{C}$.

The use of a mixed probiotc culture was reported by Evangelista et al. (2012) and Brandao et al. (2013) to favour the elaboration of fermented beverages. Also soy milk is rich in soybean-oligosaccharides such as raffinose and stachyose which are good growth substrates for lactic acid bacteria (Brandao et al., 2013). However supplementation with sugar substrate would be necessary for continual viability of bifidobacteria in soy milk yoghurt (PSMY).

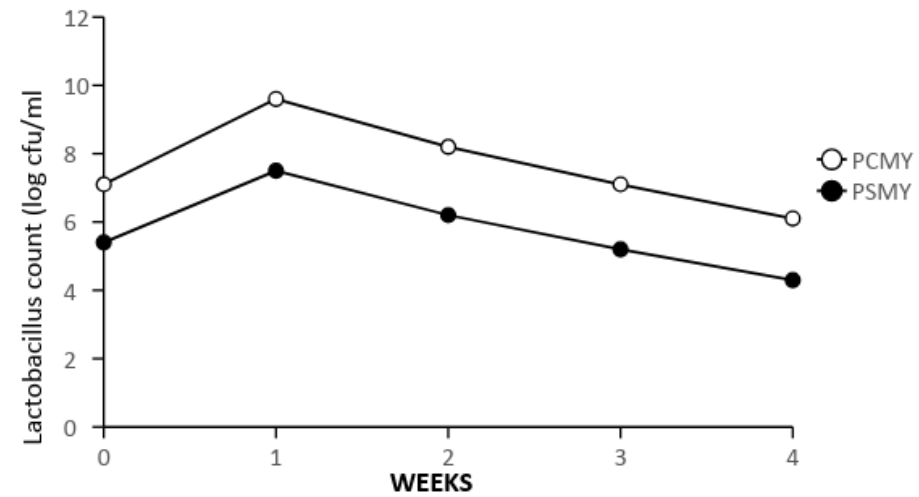

Figure 7 Total Lactobacillus counts of yoghurt sample during storage

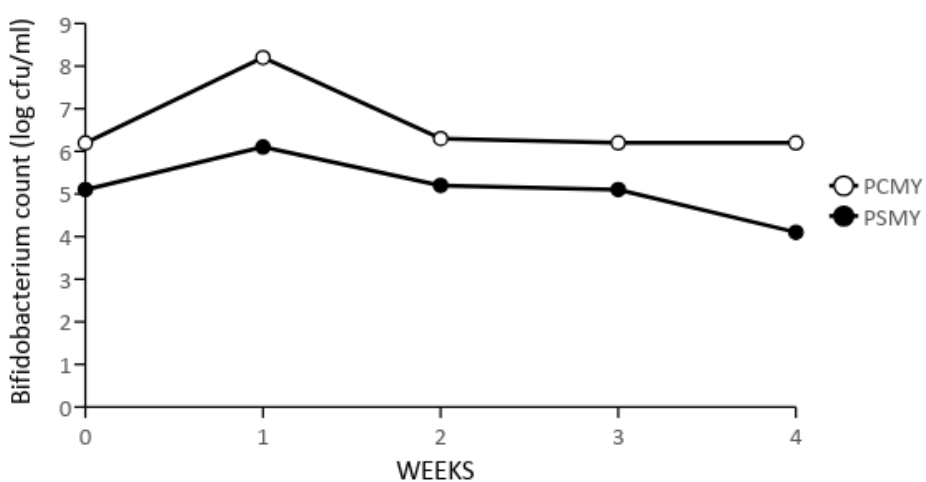

Figure 8 Total Bifidobacteria counts of yoghurt during storage 


\section{Sensory evaluation}

The result of the sensory evaluation of the panelists is presented in Figure 7 Sensory attributes affect the perception of food to be consumed and play a major role in determining consumer acceptance of food products. It was evident that the panelist preferred sample PCMY to the PSMY. Most of the panelist expressed a limiting sensory attribute of a beany aroma and after-taste in PSMY sample (Wang et al., 2015). Sensory acceptance could be influenced by the quality of the raw materials used in the processing of the yoghurts as well as the chemical reactions that might occur during the sequence of fermentation of the starter cultures used (Palacios et al., 2009; Sampson et al., 2017). Several studies have reported that inclusion of soy-beans as ingredients is associated with unpleasant beany flavour, "root" aroma and after taste (Noor et al., 2012; Sampso et al., 2017; Palacios et al., 2009).

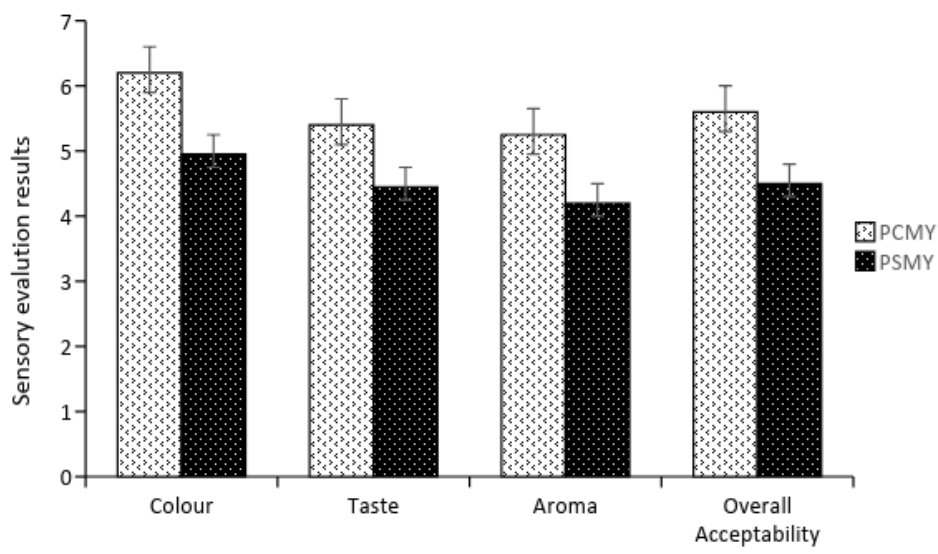

Figure 9 Sensory evaluation results of yoghurt samples at end of storage

\section{CONCLUSION}

This study showed that yoghurt samples produced from purely soy milk will compete favourably with yoghurt produced form cow milk as a prebiotic. Nutritionally, the probiotic yoghurt from soymilk met the dietary requirements of pure yoghurt without significant difference. Thus soymilk could possibly be used as alternative raw material in the production of yoghurt especially for lactose intolerance persons which will make for and a greater utilization of the soybean.

Despite the findings from these evaluations, there are needs for more research on how to mask the beany flavour of soy milk to produce sensory acceptable soy yoghurt. The choice of appropriate flavour additives would surely enhance soy yoghurt acceptability. Also more studies should be conducted to determine the shelf life of the soy milk yoghurt under different storage temperatures.

\section{REFERENCES}

AOAC. (2005). Official Methods of Analysis (18th ed.). Association of Analytical Chemist International, Gaithersburg, M.D., USA.

APHA. (1992). Compendium of Methods for the Microbiological Examination of Foods (4th ed.). American Public Health Association, Washington, USA.

Brandao, H. M., Brach, E. N., Mendonça, S. G., Brandao, W. M., Coelho, S. M \& Christ, D. (2013). Development of probiotic cultures in a symbiotic soy beverage using different types of carbohydrate. African Journal of Microbiology Research, 7(20), 2251-2258. https://doi.org/10.5897/AJMR12.1081

Bevilacqua, A., Cagnazzo, M., Caldarola, C., Ciuffreda, E., Dragano, A., Franchino, S., Lauriola, R., Pacifico, A., Corbo, M. \& Sinigaglia, M. (2012) Bifidobacteria as potential functional starter cultures. Food and Nutrition Sciences, 3, 55-63. https://doi.org/10.4236/fns.2012.31010

Evangelista S. R, Ghiselli, G. \& Filho, F. M. (2012). Development of a soy-based symbiotic beverage. Food and Nutrition Sciences, 3, 1128-1135. https://doi.org/10.4236/fns.2012.38148

Granato, D., Branco, G. F., Cruz, A. G., Faria, J. F., Nagendra, P. and Shah, N. P. (2010). Probiotic dairy products as functional foods. Comprehensive Reviews in Food Science and Food Safety, 9, 455 -369. https://doi.org/10.1111/j.15414337.2010.00120.x

IWE, M. O. (2010). Handbook of Sensory Methods and Analysis (1st ed.). Rejoint Communication Services Ltd., Enugu, Nigeria.

Kaushik, R. \& Arora, S. (2017). Effect of calcium and vitamin D2 fortification on physical, microbial, rheological and sensory characteristics of yoghurt International Food Research Journal, 24(4), 1744-1752.

Ndife, J., Abdulraheem, L. O. \& Zakari, U. M. (2011). Evaluation of the nutritional and sensory quality of functional breads produced from whole wheat and soya bean flour blends. African Journal of Food Science, 5(8), 466 - 472.

Ndife, J. (2016). Functional foods: Basics, Ingredients and Application (1st ed.). Amotees Link Services and Publishers, Kaduna, Nigeria.
Noor, A. A., Mohamad-Noor, A. Y. \& Ho, L. H. (2012). Physicochemical and organoleptic properties of cookies incorporated with legume flour. International $\begin{array}{llll}\text { Food Research } & \text { Journal, } & 19(4), & 1539-1543 .\end{array}$ https://doi.org/10.1080/23311932.2016.1172389

Palacios, O. M., Badran, J., Drake, M., Anne, R. M. \& Moskowitz, H. R. (2009) Consumer acceptance of cow's milk versus soy beverages: Impact of ethnicity, lactose tolerance and sensory preference segmentation. Journal of Sensory Studies, 24(5), 731-748. https://doi.org/10.1111/j.1745-459X.2009.00236.X

Jimoh, K. O. \& Kolapo, A. L. (2013). Effect of different stabilizers on acceptability and shelf stability of soy-yoghurt. African Journal of Food Science Research, 1(2), 015-017.

Oduro-Obeng, H. \& Plahar, W. A. (2017). Development, quality evaluation and estimated contribution of composite flour snack foods to nutrient requirements of young children aged 2 to 6 years. African Journal of Food Science, 11(9), 318 329. https://doi.org/10.5897/AJFS2017.1618

Olaoye, O. A. (2015). A study on quality parameters and shelf stability of sweetened condensed vegetable milks produced from four varieties of soybeans (Glycine max). International Food Research Journal, 22(6), 212-218.

Olaoye, O. A., Ndife, J. \& Raymond, V. I. (2017). Use of lactobacillus plantarum as starter culture and its influence on physicochemical, microbiological, and sensory characteristics of kunnu-aya produced from sorghum and tigernut. Hindawi Journal of Food Quality, 2007, 1 - 8 . https://doi.org/10.1155/2017/6738137

Osundahunsi, S. \& Sanz, Y. (2007). Ecological and functional implications of the acid adaptation ability of Bifidobacterium: a way of selecting improved probiotic strains. International Dairy Journal, 17, 1284-1289. https://doi.org/10.1016/j.idairyj.2007.01.016

Onwuka, G. I. (2014). Food Science and Technology (1st ed.). Naphtali Prints, Lagos, Nigeria.

Onwuka, G. I. (2018). Food analysis and instrumentation: theory and practice (2nd ed.). Naphtali Prints, Lagos, Nigeria.

Sampson, G. O., Duah, G. V. \& Alhassan, M. (2017). Preparation of semi-dairy yoghurt from soy bean. American Journal of Food Science and Technology, 5 (1), 1 - 5. https://doi.org/10.12691/ajfst-5-1-1

Tamine, F. C. (1997). Trends in dairy probiotic beverages. Food Research International, 41,111-123.

Trisnawati, C. Y., Srianta, I. \& Marsono, Y. (2013). Effect of corn varieties on the characteristics of soy corn milk. International Food Research Journal, 5, 1187-1190.

Wang, L., Ma, L., Li, B., Han, F., Yan, S. \& Sun, J. (2015). Evaluation of the chemical quality traits of soybean seeds, as related to sensory attributes of $\begin{array}{lllll}\text { soymilk. Food Chemistry, } & \text { 694-701. }\end{array}$ https://doi.org/10.1016/j.foodchem.2014.10.096

Xiaohong, M., Xinzhong, H., Liu, L., Xiaoping, L., Zhen, M., Jiahui, C. \& Xue, W. (2017). The quality changes and microflora analysis of commercial instant soya milk. Food Science and Nutrition, 5(1), 123130. https://doi.org/10.1002/fsn3.371 